\title{
The effect of gestational undernutrition on maternal weight change and fetal weight in lines of mice selected for different growth characteristics
}

\author{
Cathy M. Dwyer*, Christine Moinard, Kirstin M. McIlvaney, Colin A. Morgan and Lutz Bünger \\ Sustainable Livestock Systems Group, Scottish Agricultural College, King's Buildings, West Mains Road, Edinburgh EH9 3JG, \\ $U K$ \\ (Received 11 March 2010 - Revised 28 June 2010 - Accepted 1 August 2010)
}

\section{Abstract}

The present study investigated whether the genetic growth characteristics (fast or slow growing, lean or fat) of a mother influences her ability to partition nutrients to developing offspring. A total of sixty-one pregnant mice of three selected lines were used: fast-growing, relatively fat (FF, $n$ 19); fast-growing, relatively lean (FL, $n$ 23); and normal growth, relatively lean (NL, $n$ 19). On day 1 of pregnancy, mice were given either ad libitum access to food (control (C): $n$ 32) or pair-fed at $80 \%$ of $\mathrm{C}$ intake (restricted (R): $n$ 29). Feed intake and dam weight were measured daily. The weight of the mouse, organs, mammary tissue and the weight of fetuses and placentas were determined at day 18 of gestation. Overall, R dams gained less than half the weight of $\mathrm{C}$ dams during gestation. NL dams gained the most weight, and FF dams gained the least weight $(P<0 \cdot 001)$. $\mathrm{R}$ dams in the fast-growing lines mobilised significantly more body fat during gestation than the NL line $(P<0.001)$ and had a greater reduction in mammary tissue growth. The relative weight of the litter increased in $\mathrm{R}$ dams of the FF line but was reduced in both the lean lines. Undernutrition reduced fetal and placental weight, and reduced placental efficiency in all the lines. The reduction was least in the FF line and greatest in the FL line. The data suggest that selection of animals for different growth characteristics alters their response to undernutrition during pregnancy, the relatively fat line was better able to buffer its offspring from the effects of undernutrition than the lean lines, regardless of their underlying rate of growth.

Key words: Gestational undernutrition: Fetal weight: Growth characteristics: Mice

The impact of undernutrition in pregnancy, particularly on the developing fetus, has been the subject of much experimental interest in recent years. In general, nutrient restriction during early development has long-lasting consequences for the offspring including reduced birth weights, alterations in fat metabolism ${ }^{(1-3)}$, hypothalamicpituitary-adrenal axis reactivity ${ }^{(4,5)}$, changes in muscle structure and function ${ }^{(6,7)}$, reduced reproductive capacity $^{(8-11)}$ and behavioural effects ${ }^{(12-16)}$. Some of these effects can be permanent resulting in altered health profiles, for example increased obesity and hypertension in adulthood $^{(17-20)}$, and can be transgenerational in their effects $^{(21)}$. These findings have obvious implications for human health and development, but more recently there has also been concern about how this may have an impact on the development, productivity and welfare of animals kept for agriculture.

The data from animal studies suggest that genetic lines or breeds of animals may have differing abilities to cope with periods of undernutrition. For example, Scottish
Blackface and Suffolk ewes have different placental characteristics and better placental efficiency (in terms of weight of fetus supported per $g$ of placenta) is seen in the Scottish Blackface breed ${ }^{(22)}$. The Scottish Blackface breed has been adapted to surviving in a harsh environment and also has been subjected to considerably less selection pressure for rapid lean tissue growth compared to the Suffolk. Preliminary data suggest that the birth weight of prenatally undernourished lambs of different breeds are differentially affected ${ }^{(23)}$, and these lambs show differential behavioural responses after birth ${ }^{(24)}$ Elsewhere, a study comparing two lines of ewes selected for management under good and poor nutritional conditions, respectively, demonstrated that ewes selected under conditions of limited nutrition were better able to protect their fetuses from the effect of a period of undernutrition $^{(25)}$. These data suggest that there may be considerable genotype differences in the impact of undernutrition in pregnancy on subsequent offspring development. To address this in more detail, in the present study, we

Abbreviations: C, control; FF, fast-growing, relatively fat mice; FL, fast-growing, relatively lean mice; NL, normal growth, relatively lean mice; R, restricted; TRARS, thiobarbituric acid-reactive substances.

*Corresponding author: Dr C. M. Dwyer, fax +44 131535 3121, email cathy.dwyer@sac.ac.uk 
made use of the marked variation in growth available in different long-term selected lines of mice ${ }^{(26-28)}$ to ask whether the growth characteristics of the mother affected her ability to protect her developing fetuses from the consequences of undernutrition in utero. We hypothesised that lines selected for rapid lean tissue growth would prioritise their own body tissues at the expense of their fetuses more than mothers from slower growing lines. As our interest in the present study was primarily to examine the impact of selection for rapid lean tissue growth over normal growth patterns, we used lines of mice of similar leanness, but with different growth potential. Further, in order to separate the effects of leanness per se from that of rapid growth, we used a third line that also showed rapid growth but was significantly fatter than the other rapid growth line.

\section{Animals, materials and methods}

The entire protocol was reviewed and approved by the local experiments and ethics committee (Scottish Agricultural College, Edinburgh, UK), and specific procedures were done under an Animal (Scientific Procedures) Act 1986 Project Licence granted by the Home Office.

\section{Mouse lines}

Our initial studies found that some of the inbred mouse lines ${ }^{(26,28)}$ displaying the required growth characteristics for the study had poor fertility. For example, in one line, only one of the twenty mice seen with a vaginal plug after mating was found to be pregnant at day 18 gestation, and in a second line, eleven of the twenty dams produced less than five pups per litter. Therefore, to improve fertility, hybrid lines were created by mating two or more inbred lines with the required growth characteristics. The lines created were as follows: a fast growth, relatively fat (FF) hybrid line by mating Dummersdorf high and Raleigh high inbred lines (mean adult body weight $=68.4 \mathrm{~g}$ ); a fast growth, lean line (FL) by mating Roslin high and Edinburgh High inbred lines (mean adult body weight $=43.8 \mathrm{~g}$ ); and a normal growth, relatively lean line (NL: mean adult body weight $=29.9 \mathrm{~g}$ ) by reciprocal matings between two high growth, lean lines (Roslin high and Edinburgh high) and two low growth, lean lines (Roslin low and Edinburgh low). For details of the development of the parent lines used to create the hybrid lines used in the present study, see Bünger et $a l .{ }^{(26)}$. The mice used in the present study were F1 crosses of these hybrid lines.

\section{Animals and treatments}

A total of seventy-one virgin female mice of three different hybrid lines were used in the study (twenty-four FF, twenty-three FL and twenty-four NL). The mice were housed in a group of six together with a stud male of the same genotype as themselves. They were checked daily for the presence of vaginal plugs and females with plugs were weighed and placed into individual plastic MB1 cages $(45 \times 28 \times 13 \mathrm{~cm}$; North Kent Plastics Limited, Rochester, UK) with sawdust and paper nesting material. Within the line, the mice were matched for weight (within 10\%), and then one of the pair received ad libitum access to food (control: C), whereas the other was pair-fed at $80 \%$ of ad libitum intake (restricted: R). A known weight of food (a standard breeding pelleted diet: Rat and Mouse Number 3: Breeding, Special Diet Services, Witham, Essex, UK supplying $20 \cdot 2 \%$ digestible crude protein and $12.4 \mathrm{MJ} / \mathrm{kg}$ DM digestible energy) was offered to the $\mathrm{C}$ mice every morning and refusals were weighed the following day. $\mathrm{R}$ mice were then offered $80 \%$ of the intake of their paired $\mathrm{C}$ mouse that day, so the intake of $\mathrm{R}$ mice tracked 1 day behind the ad libitum intake of $\mathrm{C}$ mice. All the mice had ad libitum access to clean, fresh drinkingwater.

The mouse facility was maintained with controlled lighting ( $12 \mathrm{~h}$ light, $12 \mathrm{~h}$ dark) and at a constant temperature of $21^{\circ} \mathrm{C}$. All the mice were housed in the same room for the duration of the study.

\section{Measurements}

Of the mice, sixty-one were found to be pregnant (nineteen FF: eight C, eleven R; twenty-three FL: twelve C, eleven R; nineteen NL: twelve C, seven R) at day 18 gestation. The mice were weighed daily throughout gestation until day 18 when they were killed by placing into a $\mathrm{CO}_{2}$ chamber. Once death was confirmed, the gravid uterus was exposed, removed and weighed. The number and location of pups, including mummified or partially reabsorbed fetuses, within each horn, were recorded, and then each pup and its associated placenta were removed. Fetal weight, crown-rump length (CRL), measured with digital callipers, and placental weight were recorded for each pup. Fetal ponderal index (fetal weight/CRL ${ }^{3}$ ) and placental efficiency ( $g$ of fetus supported/g placenta) were calculated for each pup. The maternal mammary tissue, liver, heart, kidneys, spleen and fat pads (intrascapular and gonadal) were all dissected out and weighed. The ovaries were removed from the uterine horns and the number of ovulations per ovary was determined. Conception rate (number of fetuses/number of ovulations) was calculated for each dam.

The maternal conceptus-free body was weighed and then freeze-dried for the determination of body composition as described previously ${ }^{(29,30)}$.

\section{Statistics}

The effects on maternal measurements were determined using the restricted maximum likelihood procedure ${ }^{(31)}$ in GenStat 11.1, fitting litter size and the interaction between 
hybrid line and treatment. Because of the significant differences in body weight between hybrid lines, maternal organ weights were expressed as a proportion of body weight. A repeated measures restricted maximum likelihood procedure was used for maternal weight change and food intake. For pup measures, a similar model was used as for the dam measures but dam identity was also fitted as a random variable in the model.

\section{Results}

\section{Litter size and pregnancy rates}

Overall, there was no significant effect of treatment on pregnancy rate (proportion of mice seen with a vaginal plug that were pregnant at day 18 gestation: $88.9 \% \mathrm{C}$ and $82.9 \% \mathrm{R}$ ). However, the pregnancy rate for FL dams was $100 \%$ compared with $79 \cdot 2 \%$ in the FF and NL groups (Fisher's exact probability, $P=0.05$ ). There was a significant interaction between hybrid line and treatment on pregnancy rate in the two affected lines: four of the five non-pregnant dams were $\mathrm{C}$ in the $\mathrm{FF}$ group, whereas five of the five non-pregnant dams were $\mathrm{R}$ in the $\mathrm{NL}$ group (Fisher's exact probability, $P=0 \cdot 05$ ).

Litter sizes of viable pups ranged from seven to twentyeight pups. There was a significant effect of hybrid line on litter size (Table 1; $P<0 \cdot 001$ ) but no effects of treatment or interactions between hybrid line and treatment. The effect of hybrid line on litter size appeared to be due to both an increased ovulation rate in the heavier dam lines (mean number of ovulations: $\mathrm{FF}=24 \cdot 61, \quad \mathrm{FL}=21 \cdot 23$, $\mathrm{NL}=14 \cdot 01, \mathrm{SED}=0.93$, Wald $=136 \cdot 41, \mathrm{df}=2, P<0 \cdot 001)$ and an increased conception rate in the FF dams (mean conception rate: $\mathrm{FF}=0.91, \mathrm{FL}=0 \cdot 81, \mathrm{NL}=0.87, \operatorname{SED}=0 \cdot 03$, Wald $=9.90, \mathrm{df}=2, P=0.007)$. There were no significant differences between treatment groups in ovulation or conception rates.

Partially reabsorbed or mummified fetuses were found in all the groups except the R dams of the NL line. Significantly more mummified fetuses were found in the $\mathrm{FF}$ (63\%) and FL (65\%) litters compared with NL litters (26\%: Fisher's exact $P=0.05$ and 0.015 , respectively). In both the FL and NL lines, there tended to be more mummified fetuses in the $\mathrm{C}$ group compared with the $\mathrm{R}$ group ( $\mathrm{FL}=10 / 12$ v. $5 / 11$ pregnancies, Fisher's exact $P=0 \cdot 09$; $\mathrm{NL}=5 / 12 v \cdot 0 / 7$ pregnancies, Fisher's exact $P=0 \cdot 10$ ), but this relationship was not seen in the FF line $(5 / 8 v .7 / 11$ pregnancies, $P=0.66$ ).

\section{Maternal weight change and food intake at day 18 of gestation}

There were significant effects of litter size, hybrid line and treatment on proportional maternal weight change through gestation (Fig. 1), but no significant interactions between hybrid line and treatment. Overall, NL mice gained a

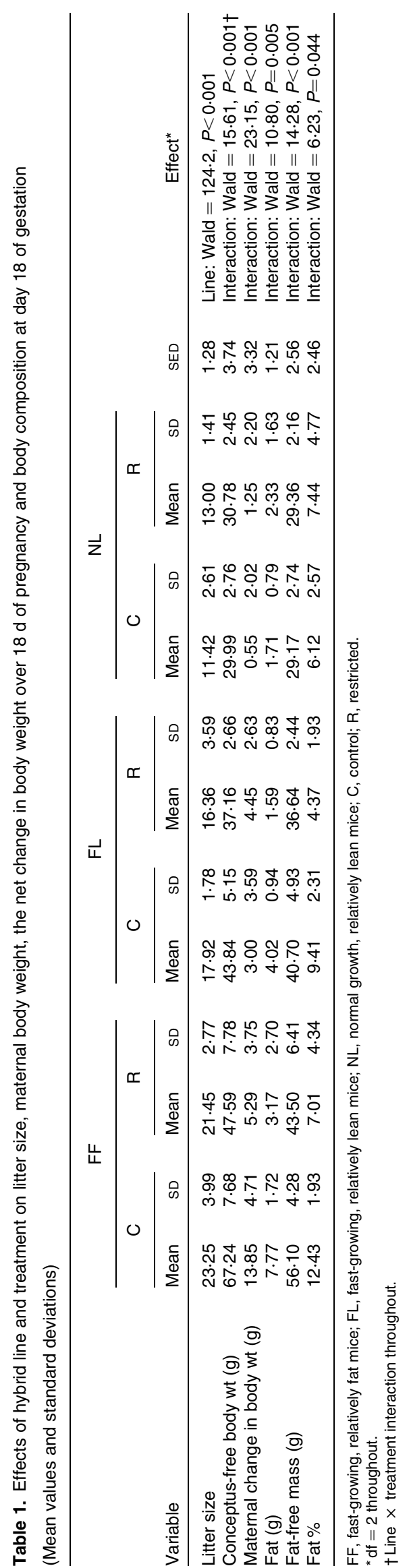




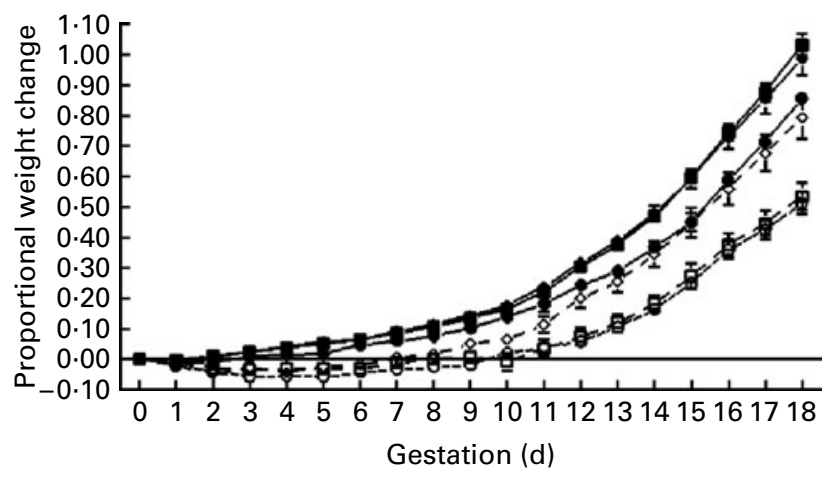

Fig. 1. Effect of hybrid line and nutritional treatment on mean maternal proportional weight gain (with standard errors) throughout gestation (relative to their starting weight) for $\operatorname{FF}(\bigcirc, \bullet), \mathrm{FL}(\square, \boldsymbol{\square})$ and $\mathrm{NL}$ dams $(\diamond, \diamond)$ allowed either ad libitum feed intake (C-0, $\mathbf{\square}, \boldsymbol{)})$ or pair-fed $80 \%$ of ad libitum

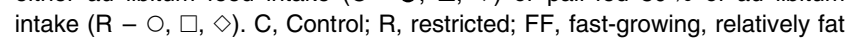
mice; $\mathrm{FL}$, fast-growing, relatively lean mice; $\mathrm{NL}$, normal growth, relatively lean mice.

significantly greater proportion of their starting weight during pregnancy than either of the fast growth lines ( $\mathrm{FF}=0 \cdot 154, \mathrm{FL}=0 \cdot 180, \mathrm{NL}=0 \cdot 249, \mathrm{SED}=0 \cdot 036$, Wald $=24.39, \mathrm{df}=2, P<0.001)$, which was apparently due to the greater weight gain in the NL-R dams compared with $\mathrm{R}$ dams of other lines, and the lower relative weight gain of FF dams (Fig. 1). Despite receiving $80 \%$ of the food of $\mathrm{C}$ animals, $\mathrm{R}$ dams gained less than half as much weight in gestation, proportional to their starting weight, as $\mathrm{C}$ dams $(C=0 \cdot 274, \quad R=0 \cdot 115, \quad S E D=0 \cdot 022$, Wald $=54 \cdot 35$, $\mathrm{df}=1, P<0 \cdot 001)$.

Food intake was scaled for body weight to compensate for the differences in maternal weight, and only the effects of litter size and hybrid line were investigated as $\mathrm{R}$ dams were fed a fixed amount depending on the intake of their matched $\mathrm{C}$ dam. Maternal food intake increased significantly through gestation (Fig. $2 ; P<0 \cdot 001$ ). Both litter size $(P<0.001)$ and hybrid line had a significant effect on maternal intake/g of body weight. NL dams ate more food than the faster growing lines (food intake $(\mathrm{g} / \mathrm{g}$ body

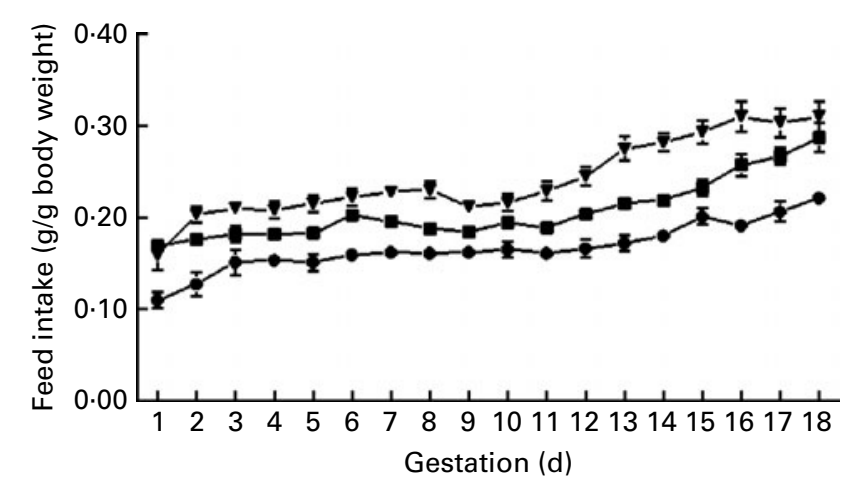

Fig. 2. Effect of hybrid line on mean maternal feed intake (with standard errors) throughout gestation, scaled for differences in maternal starting weight. ๑, FF-C; $\mathbf{\square}$, FL-C; $\mathbf{\nabla}$, NL-C. C, Control; R, restricted; FF, fast-growing, relatively fat mice; FL, fast-growing, relatively lean mice; NL, normal growth, relatively lean mice. weight): $\mathrm{FF}=0 \cdot 155, \mathrm{FL}=0 \cdot 177, \mathrm{NL}=0 \cdot 213, \mathrm{SED}=0 \cdot 011$, Wald $=46 \cdot 89, \mathrm{df}=2, P<0 \cdot 001)$.

The maternal utilisation of food to support increased growth was calculated as the ratio of weight gained per $g$ of food eaten. Maternal utilisation of food for growth increased significantly over pregnancy (Fig. 3; $P<0.001$ ) and was significantly affected by litter size $(P<0.001)$, line $(\mathrm{FF}=0.016, \quad \mathrm{FL}=0.021, \quad \mathrm{NL}=0.038, \quad$ SED $=0.0052$, Wald $=30.43, \mathrm{df}=2, P<0.001)$ and treatment $(\mathrm{C}=0.032$, $\mathrm{R}=0 \cdot 018$, SED $=0 \cdot 0032$, Wald $=19 \cdot 24, \mathrm{df}=1, P<0 \cdot 001)$. There was also a significant time $\times$ hybrid line $\times$ treatment interaction (Fig. 3; $P<0.001$ ) as restricted NL dams utilised feed for growth at a faster rate, and restricted FL at a slower rate, over the last half of pregnancy.

\section{Maternal weight and body composition at day 18 of gestation}

The maternal conceptus-free body weight at day 18 of gestation was significantly affected by both hybrid line $(\mathrm{FL}>\mathrm{FF}>\mathrm{NL}, \quad P<0.001)$ and treatment $(\mathrm{C}>\mathrm{R}$, $P<0.001)$. However, there was a significant interaction between line and treatment $(P<0.001$, Table 1) with a greater difference in maternal weight between $\mathrm{C}$ and $\mathrm{R}$ dams in the FF hybrid line (19.14 g or $29 \cdot 2 \%$ of $\mathrm{C}$ maternal body weight) compared with $7.45 \mathrm{~g}(15 \cdot 2 \%)$ in $\mathrm{FL}$ and a slight increase of $0.7 \mathrm{~g}(-2.6 \%)$ in NL. The control FF dams had a net weight gain over the course of their pregnancy (Table 1), whereas there was little net weight gain in the lean hybrid lines. The $\mathrm{R}$ dams of both the fast-growing hybrid lines had a net weight loss but the same effect was not seen in the NL line. The weight loss in $\mathrm{R}$ dams was due to a reduction in both the amount of fat and the fat-free mass of the maternal body (Table 1 ). There were, however, significant line $\times$ treatment interactions for all body composition measures (Table 1) with $\mathrm{R}$ dams of the fastgrowing lines having a $50 \%$ reduction in body fat, in comparison to a slight increase in the $\mathrm{R}$ dams of the normal growth line.

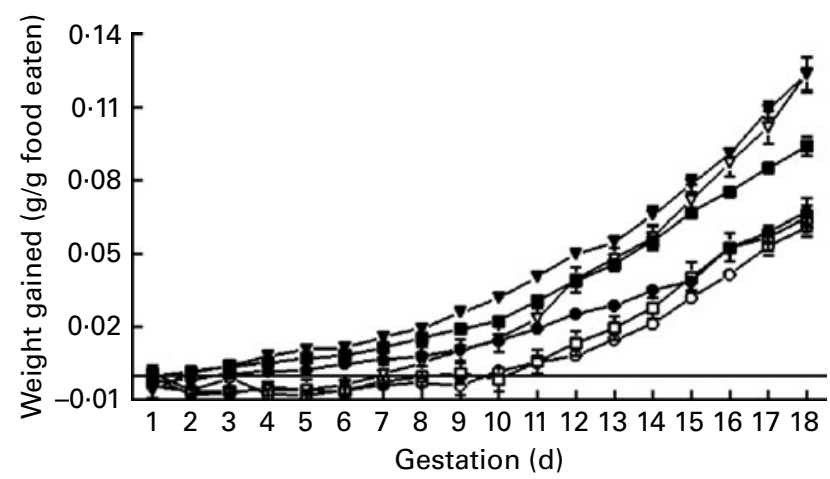

Fig. 3. Effect of hybrid line and nutritional treatment on mean maternal feed utilisation ( $g$ weight gained $/ g$ food eaten; with standard errors) to support growth throughout gestation. $\bullet, \bigcirc, F F ; \mathbf{\square}, \square, F L ; \nabla, \nabla$ NL. FF, fast-growing, relatively fat mice; FL, fast-growing, relatively lean mice; $\mathrm{NL}$, normal growth, relatively lean mice. 


\section{Maternal organ weights}

The effect of nutritional restriction and hybrid line on the proportional weight of the maternal organs is shown in Table 2. Overall, heart, kidney and liver were a greater proportion of maternal weight in the two lean lines of mice than those in the FF hybrid line. Nutritional restriction in gestation increased the proportional weight of these organs in the fast-growing lines but had only a small effect on the NL hybrid line. Spleen weights as a proportion of maternal weight were equivalent in all lines and reduced by gestational nutritional restriction in all the lines.

The gonadal fat pad, but not the intrascapular pad, tended to be proportionally heavier in the FF hybrid line dams compared with the leaner lines (Wald $=5.75$, $\mathrm{df}=2, P=0.056$ ), and both fat pads tended to be reduced in weight by maternal undernutrition in gestation, although this effect was small in the NL line (Table 2). Mammary tissue as a proportion of maternal weight was greatly affected by the nutritional restriction in all the hybrid lines with reductions as a proportion of maternal body weight of 46, 54 and $37 \%$ for the FF, FL and NL lines, respectively (Table 2; Wald $=61.96, \mathrm{df}=1, P<0.001$ ). The total weight of the litter supported as a percentage of maternal body weight was significantly influenced by both line and treatment (Table $2 ; P<0 \cdot 001$ ). However, there was a significant interaction between line and treatment with undernutrition reducing the weight of the litter as a proportion of maternal weight in the lean lines (FL and NL) and increasing it in the FF line (Table 2; Wald $=21 \cdot 95, \mathrm{df}=2, P<0 \cdot 001)$.

\section{Fetal and placental weight}

The effects of hybrid line and nutritional treatment on fetal and placental weights are shown in Table 3. Maternal undernutrition significantly reduced the weight and length of the fetus, the weight of the placenta and placental efficiency (fetal:placental weight ratio). Ponderal indices were increased with undernutrition, as fetuses were relatively longer and thinner than their ad libitum-fed counterparts (Table 3, Wald $=9.06, \mathrm{df}=1, P=0.003$ ). There were also significant effects of hybrid line on all traits except ponderal index. In general, FF dams gave birth to heavier and longer fetuses attached to more efficient placentae than other lines, and FL line had the heaviest and least efficient placentae (Table 3).

\section{Discussion}

Overall, our data suggested that there were significant hybrid line effects in the maternal response to pregnancy and that undernutrition had different effects within line in terms of maternal maintenance of pregnancy, maternal weight gain and relative changes in organ weights.
In general, in proportion to their starting body weight, the normal growth line dams ate more food, gained more weight and utilised more feed for growth than the fast-growing lines. However, the control FF dams, despite their lower feed intake and utilisation, had a net weight gain during pregnancy that was not seen in the other lines. The $\mathrm{R}$ dams gained much less weight than the $\mathrm{C}$ dams and converted less feed into growth. This effect was greatest in the FF line but was much less marked in the NL dams. There were significant effects of line and treatment on the growth of reproductive tissues (mammary, fetus and placenta), but no significant interactions between line and treatment. Undernutrition decreased fetal and placental weights and placental efficiency in all the lines and increased ponderal index. The greatest effects of undernutrition on mammary weight, fetal weight, length, ponderal index and placental efficiency were seen in the FL line and the least effect on fetal dimensions, and placental efficiency in the FF animals, NL lines were intermediate. Placenta and mammary weight were reduced least by undernutrition in the NL line compared with the other lines. Thus, although the mothers of different growth lines differed in their ability to spare their own tissues from the effects of undernutrition, they were not able to buffer their fetuses from a 20 to $30 \%$ reduction in weight by day 18 of gestation. However, there was variation between lines in the severity of effect of undernutrition, with the offspring of the FF dams being least, and those of the FL dams most, affected. In general, the data support our hypothesis that the offspring of fast-growing, lean lines of animals will be disproportionately affected by gestational undernutrition in comparison to more slow-growing or fatter lines. The data suggest that it is the dual combination of fast growth and leanness that is important as the fast-growth, fat line was less affected by undernutrition.

There were no treatment effects on the maintenance of pregnancy, litter size, embryo or fetal survival, although there were significant genotype effects. In previous studies of farm animals, both high ${ }^{(32,33)}$ and low ${ }^{(34,35)}$ nutritional planes after conception have been associated with reduced embryo survival. However, in sheep, this appears to be related to maternal maturity as effects of high nutrition reduced conception in adolescent but not mature ewes $^{(36)}$ and is also influenced by the timing of nutritional manipulations in pigs ${ }^{(37)}$. Our data suggest that, in the mouse, a relatively mild nutritional stressor, imposed immediately after conception in virgin mice, has no impact on dam fertility. However, larger litter sizes were associated with heavier maternal body weight, as has been previously demonstrated in sheep ${ }^{(38)}$. In addition, larger litter sizes are also associated with an increase in leanness in sheep and mice ${ }^{(39-41)}$, although in the present study the largest litter sizes were in the line with greatest fatness. Fetal mortality was higher in the fast-growing lines (FF and FL). However, as these lines also had the largest litters, this may have been primarily due to uterine 
Table 2. Effect of gestational nutrition on the proportional weight of maternal organs and tissues and total litter weight, scaled for hybrid line differences in maternal weight, at day 18 of gestation (Mean values and standard deviations)

\begin{tabular}{|c|c|c|c|c|c|c|c|c|c|c|c|c|c|c|}
\hline \multirow[b]{3}{*}{ Variable (\%) } & \multicolumn{4}{|c|}{$\mathrm{FF}$} & \multicolumn{4}{|c|}{$\mathrm{FL}$} & \multicolumn{4}{|c|}{$\mathrm{NL}$} & \multirow[b]{3}{*}{ SED } & \multirow[b]{3}{*}{ Effects } \\
\hline & \multicolumn{2}{|c|}{ C } & \multicolumn{2}{|c|}{$\mathrm{R}$} & \multicolumn{2}{|c|}{$\mathrm{C}$} & \multicolumn{2}{|c|}{$\mathrm{R}$} & \multicolumn{2}{|c|}{$\mathrm{C}$} & \multicolumn{2}{|c|}{$\mathrm{R}$} & & \\
\hline & Mean & SD & Mean & SD & Mean & SD & Mean & SD & Mean & SD & Mean & SD & & \\
\hline Kidney & 1.02 & 0.20 & $1 \cdot 28$ & $0 \cdot 10$ & $1 \cdot 35$ & 0.24 & 1.64 & $0 \cdot 10$ & 1.58 & 0.08 & 1.56 & 0.12 & 0.11 & $\begin{array}{l}\text { Line: } P<0.001 \\
\text { Treatment: } P=0.004 \\
\text { Interaction: } P=0.034^{*}\end{array}$ \\
\hline Liver & $6 \cdot 08$ & $1 \cdot 25$ & $6 \cdot 59$ & 0.45 & $8 \cdot 70$ & 0.54 & $7 \cdot 51$ & 0.42 & 8.45 & 0.45 & 8.06 & 0.70 & 0.46 & $\begin{array}{l}\text { Line: } P<0.001 \\
\text { Treatment: } P=0.024 \\
\text { Interaction: } P=0.006^{*}\end{array}$ \\
\hline Heart & 0.32 & 0.12 & 0.52 & 0.07 & 0.45 & 0.07 & 0.68 & 0.12 & 0.68 & 0.07 & 0.62 & 0.06 & 0.05 & $\begin{array}{l}\text { Line: } P=0.015 \\
\text { Treatment: } P<0.001 \\
\text { Interaction: } P<0.001^{*}\end{array}$ \\
\hline Spleen & 0.33 & 0.08 & 0.32 & 0.04 & 0.38 & 0.03 & 0.32 & 0.06 & 0.33 & 0.04 & 0.25 & 0.06 & 0.04 & Treatment: $P<0.001$ \\
\hline Gonadal fat & 1.56 & 0.94 & 0.69 & 0.88 & 0.60 & 0.24 & 0.27 & $0 \cdot 17$ & 0.38 & 0.21 & 0.41 & 0.18 & 0.36 & $\begin{array}{l}\text { Line: } P=0.056 \\
\text { Treatment: } P=0.12 \\
\text { Interaction: } P=0.13^{*}\end{array}$ \\
\hline Intra-scapular fat & 0.31 & 0.11 & 0.22 & 0.07 & 0.33 & 0.09 & 0.24 & 0.11 & 0.27 & 0.11 & 0.25 & 0.08 & 0.07 & Treatment: $P=0.069$ \\
\hline Mammary & $9 \cdot 24$ & 2.09 & 5.00 & 1.91 & 8.81 & $1 \cdot 10$ & 4.05 & 1.13 & 8.29 & 1.59 & $5 \cdot 20$ & 1.85 & 1.02 & $\begin{array}{l}\text { Line: } P<0.001 \\
\text { Treatment: } P<0.001\end{array}$ \\
\hline Litter & $47 \cdot 12$ & 11.9 & $52 \cdot 77$ & 4.98 & 61.04 & 7.96 & $48 \cdot 81$ & 11.08 & $68 \cdot 28$ & 8.76 & 54.57 & $6 \cdot 67$ & 3.76 & $\begin{array}{l}\text { Line: } P<0.001 \\
\text { Treatment: } P<0.001 \\
\text { Interaction: } P<0.001^{*}\end{array}$ \\
\hline
\end{tabular}

$\mathrm{FF}$, fast-growing, relatively fat mice; FL, fast-growing, relatively lean mice; NL, normal growth, relatively lean mice; C, control; R, restricted.

* Line $x$ treatment interaction. 
Table 3. Effect of hybrid line and maternal gestational undernutrition on fetal and placental weights at day 18 of gestation (Mean values and standard deviations)

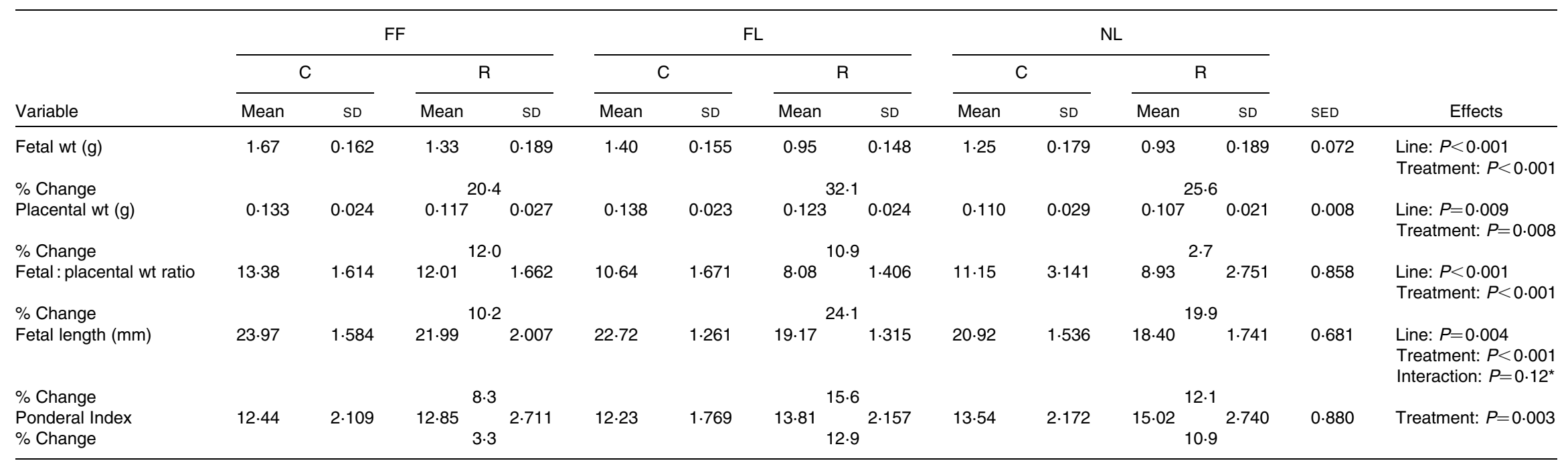

FF, fast-growing, relatively fat mice; FL, fast-growing, relatively lean mice; NL, normal growth, relatively lean mice; C, control; R, restricted.

* Line $\times$ treatment interaction. 
crowding rather than a direct effect of the maternal line growth characteristics.

Most studies of maternal undernutrition have concentrated on fetal outcomes and much less on the impact on the maternal body of experiencing a period of undernutrition during pregnancy. However, recent developments in the control of metabolism and reproduction, e.g. roles played by leptin and ghrelin ${ }^{(42)}$, have focused attention on the response of the pregnant female to nutritional signals. Our data suggest that dams of lines that were of normal growth, but genetically lean, were less affected by undernutrition, in terms of maternal weight gain and mobilisation of body reserves, than the other lines, and the FF line was the most affected. It is likely that the different lines have altered neuroendocrine responses to nutritional signals ${ }^{(30,43)}$ to support their divergent growth patterns. For example, mice divergently selected for body fatness have extreme differences in circulating leptin concentrations when both fed and fasted ${ }^{(30)}$. Thus, although these have not been investigated in these hybrid lines, it is likely that leptin concentrations were higher in the FF hybrid line than the FL or NL line. In sheep, the pattern of leptin secretions with altered nutrition is influenced by the degree of fatness of ewes at the start of the nutritional manipulations ${ }^{(44)}$. Thus, the variation in fatness in our mouse lines at the start of the study may have affected their physiological responses to undernutrition with consequences for their change in weight and efficiency of food utilisation. In addition, recent studies in mice with a targeted knockout for galanin-like peptide, implicated in the neuroendocrine control of metabolism and reproduction, suggest that galanin-like peptide plays a role in the changes in weight gain and adjustments in energy balance with underfeeding ${ }^{(45)}$. Thus the differential responses of the mice lines to undernutrition and the degree of mobilisation of fat tissue seen in the present study may be indicative of differences in underlying metabolic control.

Leptin has also been shown to affect maternal investment in offspring compared with self-maintenance in Siberian hamsters $^{(46)}$. In the present study, the NL line showed the least maternal response to undernutrition, as $\mathrm{R}$ dams were largely able to maintain their own body tissues (Table 1). These mice also had the lowest relative proportion of body fat. In contrast, the FF line, with the greatest proportion of body fat, showed the greatest mobilisation of body reserves and the most weight loss. The FF line also appeared to invest more heavily in their future offspring when resources were limited than the lean lines as litter weight as a proportion of maternal weight increased with undernutriton and pup weight reduction with undernutrition was least in this group. The data, therefore, suggest that the FF line had a greater ability to alter maternal investment in her developing offspring than the other lines, perhaps due to her greater ability to mobilise fat stores.

Although FF dams appeared able to protect their developing fetuses to some extent from the effects of undernutrition, this did not extend to the placenta, which showed the greatest proportional reduction in weight in the FF group compared with the other groups. The reduction in placental efficiency with undernutrition, as has been seen previously ${ }^{(25,47)}$, was least in the FF group, however, and may be related to placental remodelling to improve blood flow and exchange surface area as an adaptation to undernutrition ${ }^{(47-49)}$. Previous studies in sheep adapted to low nutrition have shown that they are able to maintain placental efficiency with undernutrition in comparison to ewes adapted to good nutrition ${ }^{(25)}$, and this was achieved via an alteration in placental structure to facilitate nutrient exchange. Thus, although not investigated in the present study, it seems possible that the placentas of restricted-fed FF dams may have shown greater adaptations to promote transfer of nutrients to the developing fetuses than the placentas of the other lines. In addition, the placentas of the FL line were the heaviest but the least efficient and the most affected by undernutrition, and thus the weight of the fetuses in this line were also the most affected by a restricted diet.

In conclusion, the present study has shown that different lines of mice selected for differing growth characteristics have altered responses to the effects of undernutrition in pregnancy and that this has consequences for the growth of their fetuses. The fast-growing, relatively fat line showed the greatest maternal response to undernutrition, and the slower-growing lean line the least, in terms of the impact on maternal weight gain and fat mobilisation. However, the offspring of the FF line were least affected in terms of a reduction in weight and length, and those of the FL line showed the greatest weight loss. One limitation of the present study is the lack of a normal growth, fat line which could allow complete separation of the impacts of growth and fatness on the response to undernutrition. In particular, additional studies with these lines might help to explain the apparent ability of the normal growth, lean line to withstand reductions in maternal body weight when confronted with undernutrition. Further, whether the differential effect of undernutrition has consequences for the behavioural and physiological development of the pups of different lines, and for their longer-term health, remains to be seen, and the mechanisms by which the different lines show altered responses to limited nutrition are unknown. These data also have consequences for farm animals where there has been intensive selection for animals that show rapid lean tissue growth. It seems likely that these animals will be more affected, in terms of fetal development, if nutrition is limited, than animals that are fatter or are selected for slower growth.

\section{Acknowledgements}

The present study was supported by a grant from the Scottish Government Rural and Environment Research and 
Analysis Directorate. There are no conflicts of interest. We thank Moira Stewart and John Verth for the day-to-day care of the mice and mouse facility. C. M. D. designed the experiment and wrote the paper. C. M. D., C. M., K. M. M. and C. A. M. conducted the experiment. L. B. provided the mouse lines and advised on breeding the hybrid lines and on experimental design. C. M., K. M. M., C. A. M. and L. B. provided editorial comments on drafts of the manuscript.

\section{References}

1. Edwards LJ, McFarlane JR, Kauter KG, et al. (2005) Impact of periconceptional nutrition on maternal and fetal leptin and fetal adiposity in singleton and twin pregnancies. Am J Physiol 288, R39-R45.

2. Bellinger L, Sculley DV \& Langley-Evans SC (2006) Exposure to undernutrition in fetal life determines fat distribution, locomotor activity and food intake in ageing rats. Int $J$ Obes 30, 729-738.

3. Ford SP, Hess BW, Schwope MM, et al. (2007) Maternal undernutrition during early to mid-gestation in the ewe results in altered growth, adiposity, and glucose tolerance in male offspring. J Anim Sci 85, 1285-1294.

4. Lesage J, Sebaai N, Leonhardt M, et al. (2006) Perinatal maternal undernutrition programs the offspring hypothalamo-pituitary-adrenal (HPA) axis. Stress 9, 183-198.

5. Buhl ES, Neschen S, Yonemitsu S, et al. (2007) Increased hypothalamic-pituitary-adrenal axis activity and hepatic insulin resistance in low-birth-weight rats. Am J Physiol 293, E1451-E1458.

6. Fahey AJ, Brameld JM, Parr T, et al. (2005) The effect of maternal undernutrition before muscle differentiation on the muscle fiber development of the newborn lamb. $J$ Anim Sci 83, 2564-2571.

7. Toscano AE, Manhaes-de-Castro R \& Canon F (2008) Effect of a low-protein diet during pregnancy on skeletal muscle mechanical properties of offspring rats. Nutrition 24, $270-278$.

8. Meikle D \& Westberg M (2001) Maternal nutrition and reproduction of daughters in wild house mice (Mus musculus). Reproduction 122, 437-442.

9. Rae MT, Palassio S, Kyle CE, et al. (2001) Effect of maternal undernutrition during pregnancy on early ovarian development and subsequent follicular development in sheep fetuses. Reproduction 122, 915-922.

10. Rae MT, Rhind SM, Fowler PA, et al. (2003) Effect of maternal undernutrition on fetal testicular steroidogenesis during the CNS androgen-responsive period in male sheep fetuses. Reproduction 124, 33-39.

11. Rhind SM (2004) Effects of maternal nutrition on fetal and neonatal reproductive development and function. Anim Reprod Sci 82, 169-181.

12. Almeida SS, Tonkiss J \& Galler JR (1996) Prenatal protein malnutrition affects avoidance but not escape behavior in the elevated T-maze test. Physiol Behav 60, 191-195.

13. Almeida SS, Tonkiss J \& Galler JR (1996) Prenatal protein malnutrition affects the social interactions of juvenile rats. Physiol Behav 60, 197-201.

14. Vickers MH, Breier BH, McCarthy D, et al. (2003) Sedentary behavior during postnatal life is determined by the prenatal environment and exacerbated by postnatal hypercaloric nutrition. Am J Physiol, Reg Integr Comp Physiol 285, $\mathrm{R} 271-\mathrm{R} 273$.
15. Bellinger L, Lilley C \& Langley-Evans SC (2004) Prenatal exposure to a maternal low-protein diet programmes a preference for high-fat foods in the young adult rat. Brit J Nutr 92, 513-520.

16. Landon J, Davison M, Krageloh C, et al. (2007) Global undernutrition during gestation influences learning during adult life. Learn Behav 35, 79-86.

17. Symonds ME \& Gardner DS (2006) Experimental evidence for early nutritional programming of later health in animals. Curr Opin Clin Nutr Metab Care 9, 278-283.

18. Langley-Evans SC (2006) Developmental programming of health and disease. Proc Nutr Soc 65, 97-105.

19. Meaney MJ, Szyf M \& Seckl JR (2007) Epigenetic mechanisms of perinatal programming of hypothalamic-pituitary-adrenal function and health. Trends Mol Med 13, 269-277.

20. Barker DJP, Osmond C, Forsen TJ, et al. (2007) Maternal and social origins of hypertension. Hypertension 50, 565-571.

21. Bertram C, Khan O, Ohri S, et al. (2008) Transgenerational effects of prenatal nutrient restriction on cardiovascular and hypothalamic-pituitary-adrenal function. J Physiol Lond 586, 2217-2229.

22. Dwyer CM, Calvert SK, Farish M, et al. (2005) Breed, litter and parity differences in the morphology of the ovine placenta and developmental consequences for the lamb. Theriogenology 63, 1092-1110.

23. Rooke JA, Houdijk JGM, McIlvaney KM, et al. (2010) Differential effects of maternal nutrient restriction between days one and ninety of pregnancy on performance of lambs of ewes from either a hill or lowland breed. J Anim Sci (In the Press).

24. Coombs T \& Dwyer CM (2008) Effects of prenatal undernutrition in early gestation on the ewe-lamb bond and lamb behaviour in Suffolk and Scottish Blackface sheep. Proceedings of the 42nd International Congress of the International Society for Applied Ethology, 3-9 August, Dublin, Eire.

25. Vonnahme KA, Hess BW, Nijland MJ, et al. (2006) Placentomal differentiation may compensate for maternal nutrient restriction in ewes adapted to harsh range conditions. $J$ Anim Sci 84, 3451-3459.

26. Bünger L, Laidlaw A, Bulfield G, et al. (2001) Inbred lines of mice derived from long-term on growth selected lines: unique resources for mapping growth genes. Mamm Genome 12, 678-686.

27. Bünger L, Renne U \& Buis RC (2001) Body weight limits in mice - long-term selection and single genes. In Encyclopedia of Genetics, pp. 337-360 [ECR Reeve, editor]. London/ Chicago, IL: Fitzroy Dearborn Publishers.

28. Bünger L \& Hill WG (1999) Inbred lines derived from longterm divergent selection on fat content and body weight. Mamm Genome 10, 645-648.

29. Hastings IM \& Hill WG (1989) A note on the effect of different selection criteria on carcass composition in mice. Anim Prod 48, 229-233.

30. Bünger L, Nicolson M \& Hill WG (1999) Leptin levels in lines of mice developed by long-term divergent selection on fat content. Genet Res 73, 37-44.

31. Patterson HD \& Thompson R (1971) Recovery of inter-block information when block sizes are unequal. Biometrika $\mathbf{5 8}$, 545-554.

32. De W, Ai-Rong Z, Yan L, et al. (2009) Effect of feeding allowance level on embryonic survival, IGF-1, insulin, GH, leptin and progesterone secretion in early pregnancy gilts. $J$ Anim Physiol Anim Nutr 93, 577-585.

33. Wallace JM, Aitken RP \& Cheyne MA (1994) Effects of post-ovulation nutritional status in ewes on early conceptus survival and growth in vivo and luteotrophic protein secretion in vitro. Reprod Fertil Devel 6, 253-259. 
34. Abecia JA, Sosa C, Forcada F, et al. (2006) The effect of undernutrition on the establishment of pregnancy in the ewe. Reprod Nutr Devel 46, 367-378.

35. Mani AU, Watson ED \& McKelvey WAC (1994) The effects of sub-nutrition before or after embryo-transfer on pregnancy rate and embryo survival in does. Theriogenology $\mathbf{4 1}$, $1673-1678$.

36. Annett RW \& Carson AF (2006) Effects of plane of nutrition during the first month of pregnancy on conception rate, foetal development and lamb output of mature and adolescent ewes. Anim Sci 82, 947-954.

37. Jindal R, Cosgrove JR, Aherne FX, et al. (1996) Effect of nutrition on embryonal mortality in gilts: association with progesterone. J Anim Sci 74, 620-624.

38. Kleemann DO \& Walker SK (2005) Fertility in South Australian commercial Merino flocks: relationships between reproductive traits and environmental cues. Theriogenology 63, 2416-2433.

39. Dwyer CM, Lawrence AB \& Bishop SC (2001) Effects of selection for lean tissue content on maternal and neonatal lamb behaviours in Scottish Blackface sheep. Anim Sci 72, 555-571.

40. Conington J, Bishop SC, Waterhouse A, et al. (1998) A comparison of growth and carcass traits in Scottish Blackface lambs sired by genetically lean or fat rams. Anim Sci $\mathbf{6 7}$, 299-309.

41. Armbrust TA \& Eisen EJ (1994) Reproductive performance in mice selected for divergence in body fat content. J Anim Breed Genet 111, 27-34.
42. Tena-Sempere M (2007) Roles of ghrelin and leptin in the control of reproductive function. Neuroendocrinology $\mathbf{8 6}$, 229-241.

43. Boswell T, Nicholson MA \& Bünger L (1999) Neuropeptide Y gene expression in lines of mice subjected to long-term divergent selection on fat content. $\mathrm{J} \mathrm{Mol}$ Endocrinol 23, $77-83$.

44. Miller DW, Harrison JL, Bennett EJ, et al. (2007) Nutritional influences on reproductive neuroendocrine output: insulin, leptin, and orexigenic neuropeptide signaling in the ovine hypothalamus. Endocrinology 148, 5313-5322.

45. Lemko HMD, Clifton DK, Steiner RA, et al. (2008) Altered response to metabolic challenges in mice with genetically targeted deletions of galanin-like peptide. Am J Physiol, Endocrinol Metab 295, E605-E612.

46. French SS, Greives TJ, Zysling DA, et al. (2009) Leptin increases maternal investment. Proc Royal Soc B 276, 4003-4011.

47. Dwyer CM, Madgwick AJ, Crook AR, et al. (1992) The effect of maternal undernutrition on the growth and development of the guinea pig placenta. J Devel Physiol 18, 297-301.

48. Clarke L, Heasman L, Juniper DT, et al. (1998) Maternal nutrition in early-mid gestation and placental size in sheep. Brit J Nutr 79, 359-364.

49. Roberts CT, Sohlstrom A, Kind KL, et al. (2001) Maternal food restriction reduces the exchange surface area and increases the barrier thickness of the placenta in the guinea-pig. Placenta 22, 177-185. 